\title{
The Automatic Storage and Retrieval System: An Overview
}

\author{
Hanan M. Hameed \\ Electrical Engineering Dept. \\ University of Basrah \\ Basrah, Iraq
}

\author{
Kharia A. Al Amry \\ Electrical Engineering Dept. \\ University of Basrah \\ Basrah, Iraq
}

\author{
Abdulmuttalib T. Rashid \\ Electrical Engineering Dept. \\ University of Basrah \\ Basrah, Iraq
}

\begin{abstract}
In this paper an overview on automated storage and retrieval system AS/RS is denoted. In industries AS/RS systems are the main task that designed for automated storage and retrieval of things in manufacturing where their application vary widely from simple storage and retrieval system for small parts to central systems where production, assembly, and manufacturing operations are concentrically located around them. The selection of the storage system depends upon the available space, weight of items to be stored, method of storage operation and another factors that take the important role in the design of the automated storage and retrieval systems. This paper will have all argument that needed to construct AS/RS system in a survey form which will gives us a highlight about the factors that consider the backbone to build the warehouses. The performance of AS/RS will be the result for interaction of many complex and stochastic subsystems. The differences among the surveyed approaches are discussed and the results are summarized.
\end{abstract}

\section{General Terms}

Automated storage and retrieval system.

\section{Keywords}

Multi- robot system, AS/RS, warehouses, workstation.

\section{INTRODUCTION}

The Automatic Storage and Retrieval System (AS/RS) generally it can be known as material handling support systems those are in majority used in automated factories, distribution centers, warehousing and non-manufacturing environment.

Basically, Warehouses can be classified into three types:

- Distribution warehouses

- Production warehouses

- Contract warehouses.

In distribution warehouses, products from different suppliers are received and stored for delivery to several customers. Production warehouses are usually used for storing raw materials, semi-finished products and finished products in a production facility. In a contract warehouse, warehousing operations are performed on behalf of one or more customers [1].

Today, quite recently appreciable attention has been going in the direction of automation for storage and retrieval system (AS/RS) by the industrial companies. AS/RS represent an innovation alternative to controlling and managing warehouse. Many benefits can be obtained from the automation of AS/RS systems such as saving in labor costs and floor space, the ease and the speed of handling items and improved throughput level (Fig. 1) show basic element of general AS/RS system that consist of one or more storage aisles that are serviced by a Storage/Retrieval machine. The stored material are held by a system of storage racks and aisles[2]. The S/R machine are used to deliver and retrieval materials in and out of inventory. There are one or more input/output stations in each AS/RS aisle for delivering the material into the storage system or moving it out of the system. In AS/RS terminology, the input/output stations are called Picked and Deposit station [3].

For mobile robot AS/RS system S/R machine will be a mobile robot that take the roll of $S / R$ machine for storage and retrieval material between rack and input/output station so, this research will discussing the development in AS/RS system reaching for using the mobile robot for these systems (Fig. 2) where the term Flexible Manufacturing System generally means a fully automated system that consist of four basic elements which are:

$$
\begin{array}{ll}
\text { - } & \text { Robot } \\
\text { - } & \text { Morkstation } \\
\text { - } & \text { Computerial transport and storage system } \\
&
\end{array}
$$

\section{HISTORY OF AS/RS}

The AS/RS is a major category of material handling equipment. There are primarily two types of AS/RS, unit-load AS/RS and the mini-load AS/RS. AS/RS usually consists of conveyors, storage racks $S R$ and automated $S / R$ machine that can travel along narrow aisles between the SR to store and retrieve loads. The $S / R$ machine can manipulate either pallets (unit-load system) or totes (mini-load system) [5]. Over the past 50 years, many studies of AS/RS had been performed within the material handling research community. The intensive development of AS/RS began with the development of informational and computer science. Hausman et al. (1976), Graves et al. (1977) presented travel time models for AS/RS assuming that the SR was square-in-time, which meant that times to the most distant column $t x=\mathrm{L} \mathrm{SR} / \mathrm{vx}$ and tier ty $=$ H SR / vy (L\&H length and height ) were both equal (tx $=$ ty).Distance IR sensor.

They analyzed different storage strategies, e.g. randomized, turnover based and class-based storage assignment rules. Gudehus (1973) presented principles for calculations of the cycle times for the Single Cycle SC and Dual Cycle DC. In the case of the SC the S/R machine could perform one storage or retrieval request, only. More advanced is the DC where the storage and the retrieval request are done simultaneously by the $\mathrm{S} / \mathrm{R}$ machine. With regard to other cycle time expressions, he considered the impact of the acceleration and deceleration rate on travel times. 


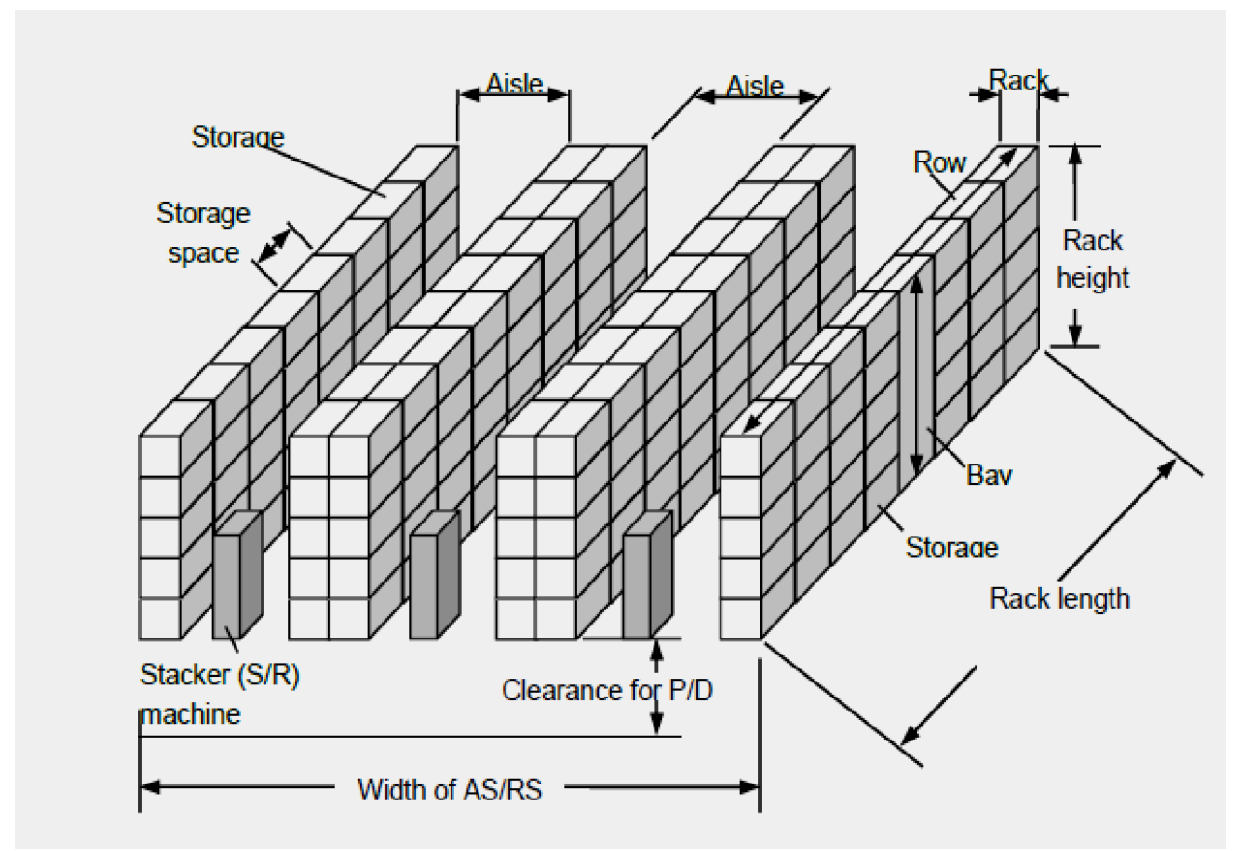

Fig. 1 General form of Basic Automatic Storage and Retrieval System.

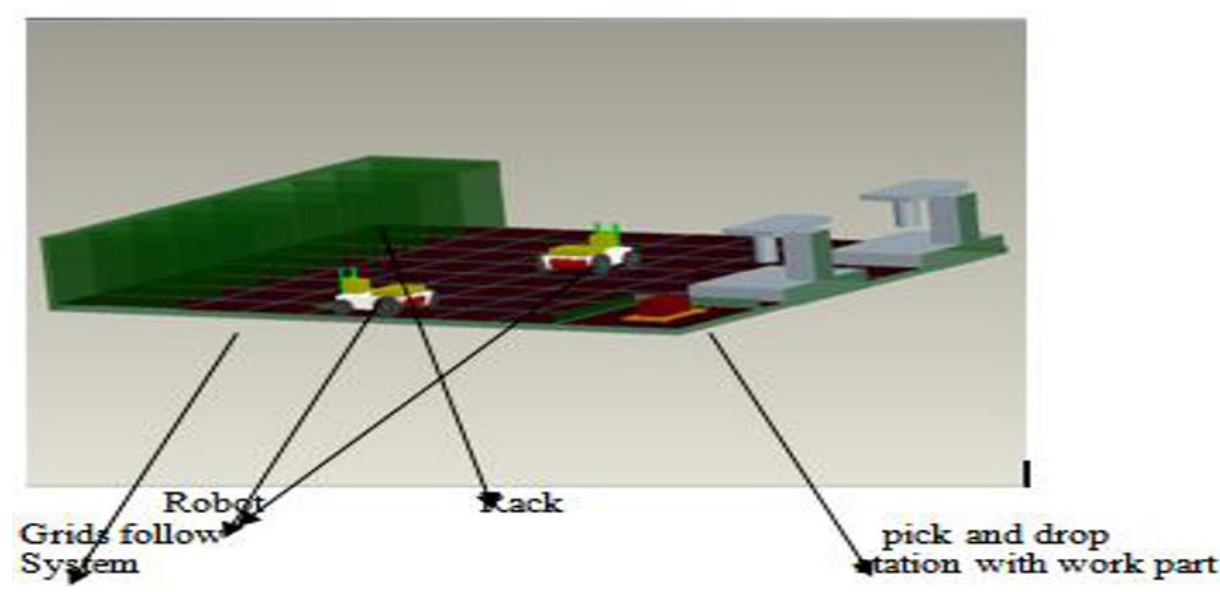

Fig. 2 .Layout of the Robotic AS/RS System.

Bozer and White (1984) presented an analytical travel time model for calculating the SC and DC for non-SIT (Square-InTime) racks. Their models were based on randomized storage and retrieval with different $\mathrm{I} / \mathrm{O}$ configurations of the input queue. Their analytical travel time model was based on the assumption that the $S / R$ machine travels all the time at constant velocity. Hwang and Lee (1990) presented travel time models by considering the operating characteristics of the S/R machines for AS/RS and non-SIT racks. Sari et al. (2005) have presented the travel-time models for the 3D flowrack AS/RS. They have introduced the flow-rack, where Transport Unit Load (TUL) loaded by the S/R machine by one end of the rack, travels to another end of the rack to be retrieved. For the storage operation, the S/R machine operates in the same way as the $S / R$ machine in the unit-load AS/RS. However, the retrieval operation for a particular TUL requires that the S/R machine removes all TUL stored in front of the requested TUL. The acceleration/deceleration effect on the travel time was not considered by the authors. Lerher et al. (2006) developed analytical travel time models for multi-aisle AS/ RS by considering the operating characteristics of the S/R machine. Using the proposed analytical travel time models, average travel time can be evaluated. Gu et al. (2007) presented a comprehensive review of research on warehouse operation. De Koster at al. (2008) have presented an optimal storage rack design for the $3 \mathrm{D}$ compact AS/RS. They have introduced the combination of the $S / R$ machine for TUL movement in the horizontal and vertical directions and the system of inbound and outbound conveyors (powered or nonpowered) for the depth movement. Roodbergen and Vis (2009) presented a comprehensive explanation of the current state-of-the-art in AS/RS. Rouwenhorst et al. (2000) presented a comprehensive review of warehouse design and control. Lerher et al. (2011) presented simulation analysis of a miniload multi-shuttle AS/RS. Recently Bortolini et al. (2015a) proposed an extension for analytical models when computing the expected travel time for the SCs and DCs of AS/RS in three-class-based storage systems. Later, Bortolini et al. (2015b) proposed non-conventional easy-applicable configuration for unit load warehouses with diagonal crossaisles. Accorsi et al. (2015) presented time and energy based assignment strategy for unit-load AS/RS warehouses. Janilionis et al. (2016) presented a comparison between routing algorithms for storage and retrieval mechanisms in cylindrical AS/RS [6]. E. Vijayaragavan, Sanketh Bhat, Abhishek Patel and Divyang Rana at 2018a perform study to 
design and analyze of a mobile robot for storage and retrieval System wherein a load of $550 \mathrm{~N}$ was applied on the robot, to simulate the weight of the storage rack. The results of the analysis are discussed and their implications on the performance of the robot are studied, which help in assessing the performance and efficiency of the robot with respect to its aim [7]. Imen Kouloughli, Pierre Castagna and Zaki Sari at $2018 \mathrm{~b}$ presented a completely new model named SRMAS (Storage and Retrieval for Multi-Agent System) that developed a novel and original because it merges two techniques carefully chosen and adapted to AS/RS gravitational conveyors which led to a tidy rack [8]. Also, A. T. Rashid, F. R. Ali and O. T. Rashid presented several algorithms that deal with the enhancement the length of the paths and the time of arrival in the static and dynamic object store system using the line follower robot and representing the trajectories by the Bezier curve and the digital differential analyzer algorithms [9-13].

\section{THE STORY OF AS/RS SYSTEMS}

In typically configuration, the $\mathrm{S} / \mathrm{R}$ machine carries at most one pallet. Pallets for storage arrive at the input station and wait at an accumulator conveyor until the $S / R$ machine transports these to their storage locations. This makes it necessary to always select the first pallet from the input queue, i.e. First Come First Served (FCFS). The S/R machine deposits retrieval loads at the output station. The S/R machine has three independent drivers for horizontal, vertical and fork movement. Hence the travel time of the $S / R$ machine is measured by the maximum of the isolated horizontal and vertical travel times. Figure (3) gives an overview of AS/RS systems, based on the type of crane, type of the loads and the types of racks that may be used. The overview also includes carousals and mobile racks, which are usually not considered as part of the classical AS/RS systems [14].
AS/RS system that can be defined as a combination of equipment's and controls which automatically handle, store and retrieve materials with great speed and accuracy, without direct handling by a human worker[15].In general automated storage and retrieval system is a set of structured parts that at the end gives us AS/RS systems such as single or more than this of aisles which consist of multi-tiered racks; stacker crane ( $\mathrm{S} / \mathrm{R}$ machine); input/output (I/O) stations ; accumulating conveyors and a central supervisory computer and communication system. AS/RSs require serious analysis during the initial design phase because at this stage the designers determine the capacity and throughput system. For example, during the design phase, managers make decisions on the rack configuration and capacity (single or double depth), the number of aisles and storage/retrieval machines ( $\mathrm{S} / \mathrm{R}$ machine) as well as the location of the Input/output station (I/O station). Once the AS/RSs are implemented, a number of control decisions must be made to obtain the performance. These control decisions include decisions on storage policies, the location point of the $S / R$ machine and scheduling, etc. [16].

In order to give a comprehensive study about AS/RS must be we look forward for the steps that required to structure these systems [15]. The main stages for design any AS/RS is physical design stage and decision design stage. So for physical design stage several types of AS/RS are generally classified according to their physical configuration, namely.

- The number of $S / R$ machines and their capacity,

- The disposition of racks and aisles in the system.

- The positions of the input/output station,

- The depth of the racks i.e. maximum number of products that could be stored in the same cell.

\section{DEFINTION OF THE AS/RS}

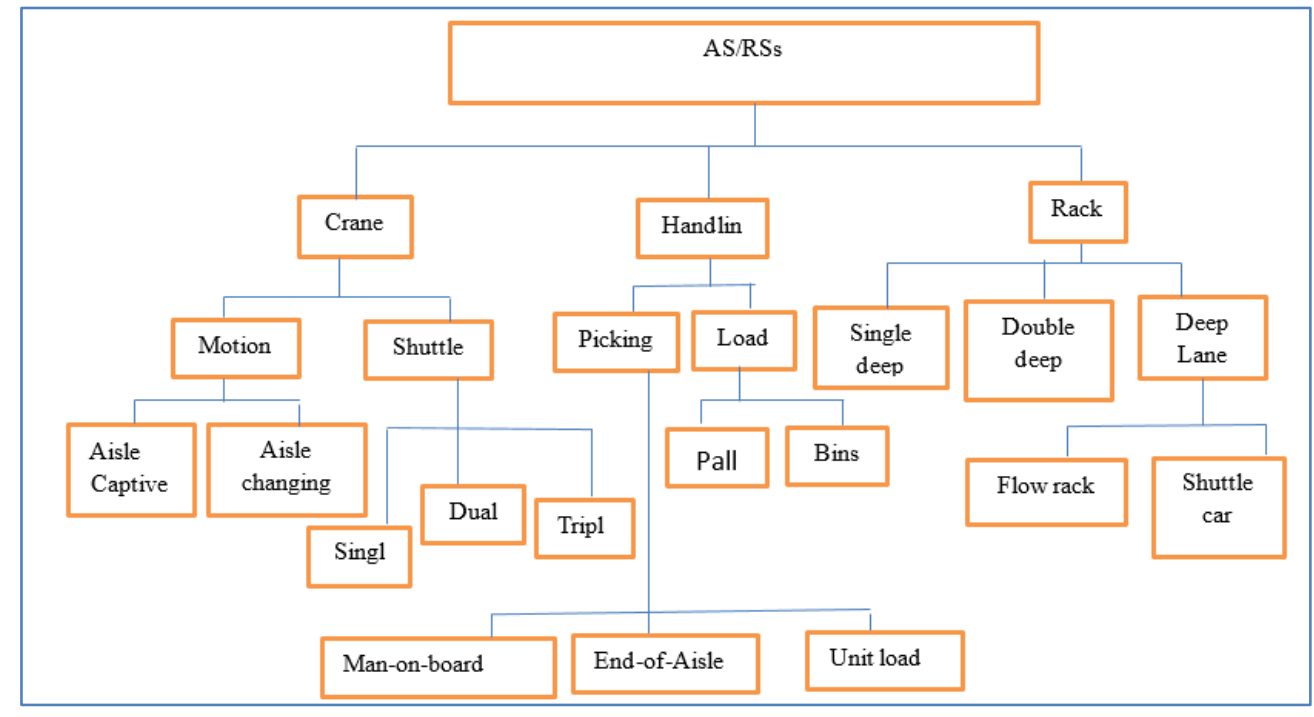

Fig. 3 Various System Concepts for AS/RSs.

Several AS/RS configurations are used in manufacturing systems and distribution centers, such as: unit-load, miniload, man-on-board, deep-lane and flow-rack [17]. While the application of control policies must manage the system in order to obtain the maximum profitability. Sequencing the storage and retrieval requests is one of the important policies. The company has to determine the sequence in which the storage and retrieval requests are conducted in order to maximize the performance of the AS/RS system. The performance measures may differ according to what the company want such as travel time per request, number of requests handled per time period, total time required to handle a certain number of requests, waiting times of the cranes, waiting time of requests to be stored/retrieved $[18,19]$. 


\section{TYPES OF AS/RS}

AS/RS can arrange warehouse management for material handling system where without automation, filling higher quantities of smaller orders means more pickers traveling through a distribution center. Eventually, at about 3,000 orders per hour, operations hit a tipping point in which foot traffic clogs thoroughfares and operations hit a productivity plateau. Rather than just refining manual processes, highly automated systems and fulfillment workflow modifications work together to deliver necessary increases in speed and accuracy. AS/RS enables different, more effective methodologies to solve the challenge of high-throughput ecommerce fulfillment [20]. Figure(4) shows general form of AS/RS system with main unit that required for any AS/RS system .So for this, can be divide the AS/RS system according to the method of handling a load to four type :

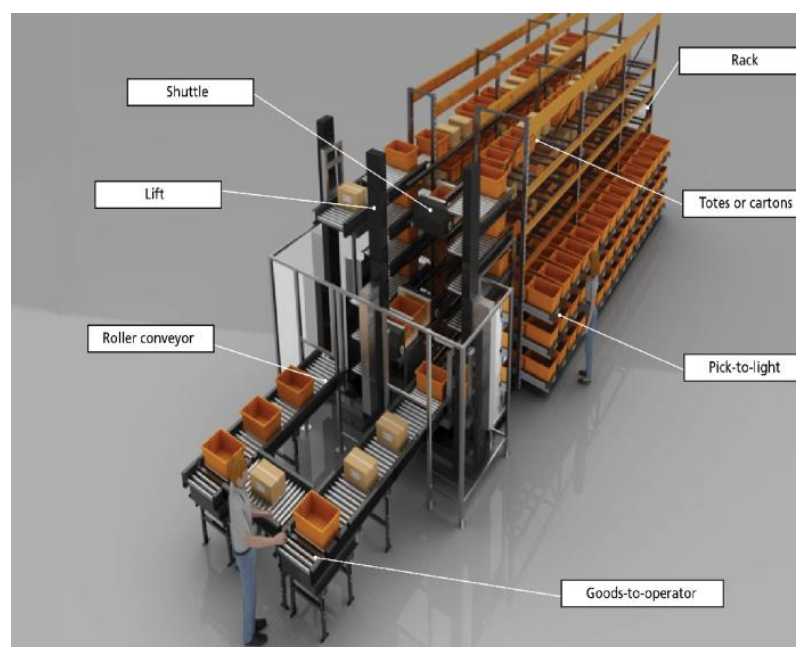

Fig. 4 General form for AS/RS System

1. Unit load AS/RS: is used to store and retrieve loads that are palletized or stored in standard-sized containers .Entire unit load is carried by forklift trucks, conveyors, etc.. Unit load stored and retrieved from AS/RS system in a certain interval of time[21].

2. Mini load System:. This system is designed to handle small loads such as individual parts, tools, and supplies that are contained in bins or drawers in the storage system. Total storage volume is less than unit load system .Such a system is applicable where the availability of space is limited

3. Man-on-board: This system allows storage of items in less than unit-load quantities. Human operator rides on the carriage of the SR machine to pick up individual items from a bin or drawer where instead of retrieving entire load automatically man will be ride over S/R machine and pick only one item from unit load.

4. Deep -lane AS/RS : This is a high-density unit load storage system that is appropriate for storing large quantities of stock. The items are stored in multi deep storage with up to 10 items in a single rack, one load behind the next. Each rack is designed for flow-through, with input and output on the opposite side. Picker located at the end of aisle can pick required few items from unit load and S/R crane restore the unit load to the rack.

\section{AS/RS DESIGN DECISIONS}

Design decision consist of physical design and control policy , so Tab. (1) shows an over view for design decision for general AS/RS system. AS/RS design decision consisted of two stage the first stage called physical design while the second stage is called control design. The physical design stage consists of two rules that specifies physical base for the system. The choice of the AS/RS type and the selected of the system that must be configured. Then these parameters include: Number of aisles, the rack structure, as shown in Fig.(5) Number of aisles, Product characteristics, required throughput, required storage space available land space and etc.

Table (1) An over view of Design Decision for AS/RS

\begin{tabular}{|c|c|}
\hline $\begin{array}{l}\text { Class of } \\
\text { problems }\end{array}$ & Decision to be made \\
\hline $\begin{array}{c}\text { System } \\
\text { configuration }\end{array}$ & $\begin{array}{l}\text { Number of aisles } \\
\text { Height of the storage racks } \\
\text { Length of the aisles } \\
\text { Equally sized or modular storage } \\
\text { locations } \\
\text { Number and location of the I/O points } \\
\text { Number of crane per aisle } \\
\text { Number of order pickers per aisle (if } \\
\text { any) }\end{array}$ \\
\hline $\begin{array}{c}\text { Storage } \\
\text { assignment }\end{array}$ & $\begin{array}{l}\text { Storage assignment method } \\
\text { Number of storage classes } \\
\text { Positioning of storage classes }\end{array}$ \\
\hline Batching & $\begin{array}{l}\text { Type of batching (static or dynamic) } \\
\text { Batch size (capacity or time based) } \\
\text { Selection rule for assignments of orders } \\
\text { to batches }\end{array}$ \\
\hline Sequencing & $\begin{array}{l}\text { Sequencing restriction (e.g., due dates) } \\
\text { Type of operation (single or dual } \\
\text { command) } \\
\text { Scheduling approach (block or } \\
\text { dynamic) } \\
\text { Sequencing method }\end{array}$ \\
\hline Dwell- point & $\begin{array}{l}\text { Type of positioning (static or dynamic) } \\
\text { Location where idle cranes will be } \\
\text { placed }\end{array}$ \\
\hline
\end{tabular}




\section{Physical design and related decisions}

\begin{tabular}{|l|l|}
\hline System Choice & $\begin{array}{l}\text { System Configuration } \\
\text { - Unit load AS/RS } \\
\text { - Deep-lane AS/RS } \\
\text { - Mini load AS/RS } \\
\text { - Man-on-board AS/RS } \\
\text { - Automated item-retrieval system } \\
\text { - Verticallift storage modules (VLSM) }\end{array}$ \\
\hline
\end{tabular}

\section{Performance measurement}

Examples of performance measures:

- Travel time estimates

- Throughput estimates

- Utilization of rack and stacker crane

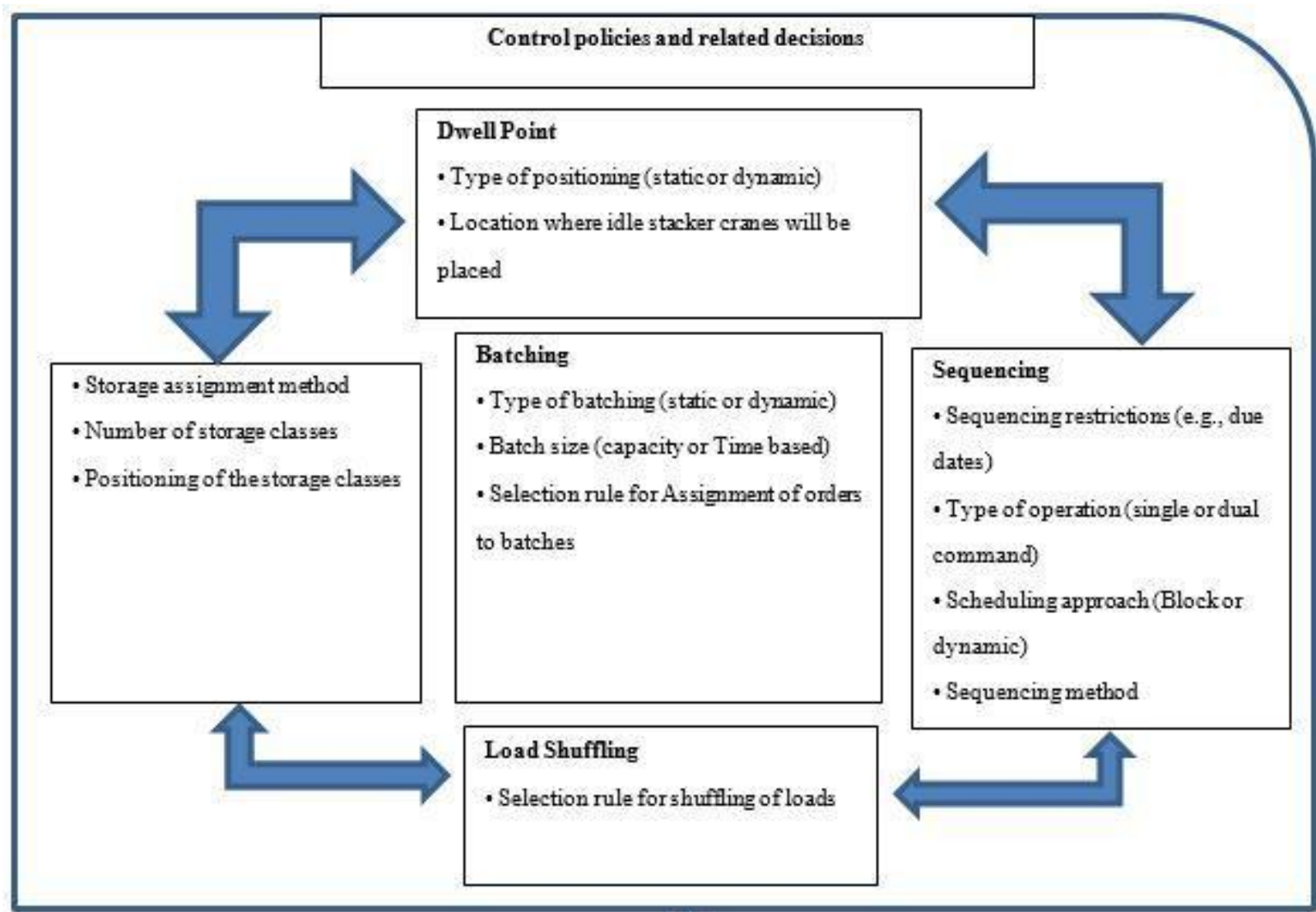

Design StorageAssignment and control of other material handling systems in the facility

Fig. 5 Design of an AS/RS and Related Decisions. 


\subsection{Physical design}

Typically when we designing an AS/RS system where the first step is Physical system design which can be defined as a configuration and dimensions of the system. System can be configured based upon previous available data, space availability and requirement, available budget and required throughput from system. System can be configured as:-

- Load size to be handled.

- Size parameters such as number of rows, number of bays in each row, individual storage space dimensions, number of storage spaces required.

- Number of aisles, Rack height and Length of Rack, Number of $S / R$ machine required.

- Selection of storage spaces such as Equal sized or modular to face variable dimensions.

- Location of input-output station [22].

Rack structured :-The rack structured consider the important step in the physical design for AS/RS system where there are two type of rack system either dynamic or static, this classification depends on the behavior of the rack system. In a dynamic rack system, the rack moves itself to bring the required a Stock Keeping Unit (SKU) to the pickup point while a static rack system is a rack system, where there is no ability for the rack to change the storage locations of SKUs within it through its own movements, as in the shelf rack system. An integrated rack system another form of rack where there are some automated mechanisms are integrated with the rack system. There are two types of integrated system. Movable racks, such as those of the Kiva system, use a driverless vehicle or robot that used to bring the rack to the pick-station and the other type is static rack includes a robot or automated mechanism built within the rack system (integrated in), as in auto store[23].

\subsection{Control design}

\subsubsection{Dwell-Point Policy}

A dwell point is an idling location of a Storage/Retrieval (S/R) machine when it becomes idle.[24] We determine a dwell point position which minimizes the expected travel time to the position of the first operation after the idle period. An effective dwell point policy may reduce the response times of the AS/RS, since the S/R machine typically performs a sequence of operations following an idle period. Hence, if the first operation is advanced, then all operations within the sequence are completed earlier [25].

Typical dwell point rules include:-

1. Dynamically position the $S / R$ machine at a location that minimizes the expected $S / R$ machine travel or response time from dwell point to the points of need.

2. Dynamically position the $S / R$ machine at a location that minimizes the maximum $S / R$ machine travel or response time from dwell point to the points of need.

3. Always position the $S / R$ machine at the input station whenever idle.

4. Always position the $\mathrm{S} / \mathrm{R}$ machine at the output station whenever idle

5. Always position the $\mathrm{S} / \mathrm{R}$ machine at the mid-point location in the rack whenever idle.
6. Dynamically position the $S / R$ machine at the last location it visited following the completion of either a single command or a dual command cycle [21].

\subsubsection{Input / Output Position policy}

Input-output locations. There is one input and one output zone (I/O). The input zone is used to introduce full boxes from outside the system and has limited capacity. The output zone is used to remove empty, faulty or out- dated boxes. When a box arrives at the output zone, it automatically leaves the system. The functionality of the output differs from the standard AS/RS problem, where it is used to satisfy the customers' requests. This function is made by the picking zones [26].

The position of the I/O station(s) is also a factor that affects the AS/RS operation. Bozer and White (1984) analyzed and derived the expected travel time of the following alternative configurations for the $\mathrm{I} / \mathrm{O}$ station:

1. Input and Output at opposite ends of the aisle.

2. Input and Output at the same end of the aisle, but at different elevations.

3. Input and Output at the same elevation, but at a midpoint in the aisle.

4. Input and Output elevated at the end of the aisle.

\subsubsection{Routing and Sequencing Type of operation policy}

Cycle time term refers to the time an order takes from its entrance to the system until it reaches the shipping area. The cycle time has a close relationship with the customer service level and thus with customer satisfaction. This is due to the fact that customers usually expect timely delivery. The operation time is not the only factor that effects the cycle time, however, there are many other factors such as palletizing time, transportation time within the whole process and also the packaging time. Storage and picking strategies have a substantial effect on the cycle time. [27]

The Type of operation time defines which command cycle is applied to operate an AS/RS. In a single command cycle (SC), either a single storage or a single retrieval operation is performed. A storage cycle consists of picking up the load at the I/O point, traveling of the $\mathrm{S} / \mathrm{R}$ machine to the storage position, placing the load into the rack and returning back to the I/O point. A retrieval cycle is performed similarly. Consequently, during a storage cycle the return travel is an empty run of the S/R machine, while for a retrieval cycle, the travel to the storage position is an empty run.

\subsubsection{Storage location assignment policy}

Storage location assignment is a set of rules that determines where incoming storage totes will be located in the storage rack [28] or A storage assignment method is a set of rules which are used to assign items to storage locations [29] or the selection of open locations for incoming unit loads. There are three storage assignment policies random storage, full turnover storage and class-based storage.

\section{Random a storage assignment policy}

Random storage is a completely shared storage policy where all incoming storage totes can be stored in any aisle and any open location in the rack. Also it allows products to be stored anywhere in the storage area. Within a storage class, items are randomly stored .The name, the open locations in random storage are chosen because of an open location selection rule 
instead of a random choice. One basic rule important here is closest open location (COL). This means that an incoming tote is stored to the closest unoccupied location from the $\mathrm{I} / \mathrm{O}$ point, with respect to travel time. [30].

Closest-open-location storage assignment

In practice, incoming items (e.g. on a pallet) are often allocated to the closest empty location. 'Closeness' here is defined by the travel distance from the input/output (I/O)

Point (or depot) to the storage location

\section{Dedicated storage assignment policy}

Materials are assigned to predetermined locations based on throughput and storage requirements or each item has its own storage location. To minimize the travel distance, the closest to-depot storage locations are commonly reserved for items with a high turnover and little storage space occupation. An early type of this storage assignment method is the COI-based storage assignment, where the COI of an item is defined as the ratio of the required storage space to the order frequency of the item The COI-based method sort's items by increasing $\mathrm{COI}$ ratio and locations on increasing distance from the $\mathrm{I} / \mathrm{O}$ point. Next, items are assigned one by one to locations in this sequence (items with the next lowest COI ratio to next quickest-to-access locations).

\section{Class based storage policy}

Figure( 6 ) shows the class based assignment that It partitions all products into a number of classes and reserves a physical portion within racks for each class. This storage policy is generally managed according to the dispatching rule based on the cube per order index (COI) introduced by [31]. It is defined as the ratio of the number of storage addresses allocated to an item and the number of transactions per period. This rule is applied by routing incoming items with lowest values to the most accessible (nearest to I/O points) storage addresses of a facility. In class-based storage policy each class is assigned to a block of storage locations: for this reason the size of classes and distributions of products among them have to be properly designed. Within each block of storage locations, material is generally stored randomly.
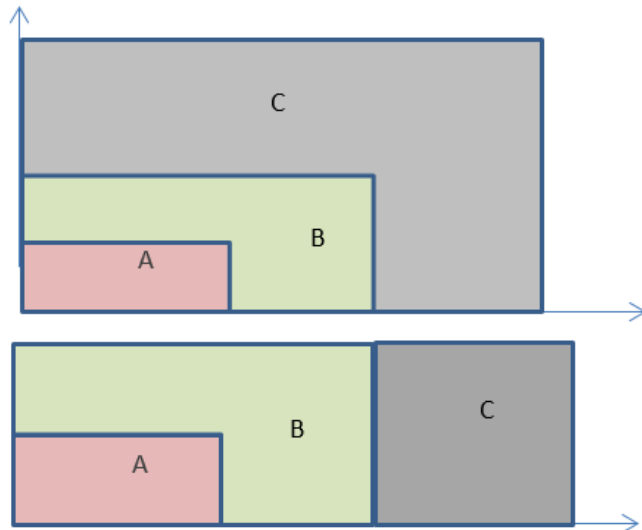

Fig. 6 Atypical Zone Positioning for three Classes in Square in Time Rack (upper part) and Rectangular Rack (lower part).

\section{ORDER BATCHING}

When there are a required items that are collected on tours through the warehouse, where the number of stops on each tour is limited by the available capacity of the picking vehicle /picking device on the one hand and by the capacity requirement of the items to be picked on the other hand.
Customer order can be combined (batched) into to picking orders (batches) until the capacity of the device is exhausted. Capacity can be expressed in the number of customer order. Splitting of customer order, i.e. , the inclusion of items from the same customer order in several picking order[32]. Usually, an order is selected, to be included in a batch, based on a measure of the 'distance' from the order to the seed order of the batch.

\section{CONCLUSION}

This paper summarizes the various components in an automated storage and retrieval system, lists also the benefits of automating a company's storage operation. Details of the various control strategies are included and a summary of the performance measures applied to such systems. The findings from this overview are that there is currently a large amount of research on-going with particular emphasis on improving throughput by analyzing storage, retrieval and dwell point strategies. The best recorded performance was content a current dwell point, simultaneous travel, dual control, free nearest storage and nearest retrieval strategies selected in combination. In general, dual control improved performance (in terms of throughput), simultaneous travel was found to be better than rectilinear travel, dwell point at origin gave very poor results, and a dwell point at current, pick point or deposit point appears best considers the popularity of items, not their space occupation. COI-based storage is that the volume-based assignment only considers the popularity of items, not their space occupation. The pick volume of an item can be expressed in number of units or pick lines during a certain time horizon. The difference between this method and COIbased storage is that the volume-based assignment only considers the popularity of items, not their space occupation.

\section{REFERENCES}

[1] Matej Borovinšek, Banu Y. Ekren, Aurelija Burinskienè, Tone Lerher," MULTI-OBJECTIVE OPTIMISATION MODEL OF SHUTTLE-BASED STORAGE AND RETRIEVAL SYSTEM "Vilnius Gediminas Technical University (VGTU) Press , Transport, Vol.32(2): pp.120-137, 2017.

[2] Renata Kudryavtseva ," Simulation-based analysis of performance of automated storage and retrieval system Storage/retrieval (S/R) crane performance “, Bachelor's thesis Technology, communication and transport Degree Program in Logistics Engineering, May 2018.

[3] Salah Bashir," THE IMPLEMENTATION AND ANALYSIS OF A TENDON-BASED STEWARTGOUGH-PLATFORM (SGP) FOR AN AUTOMATED STORAGE AND RETRIEVAL SYSTEM FOR MINILOAD”, PhD thesis, 5, 2013.

[4] Smita U. Chakole," development of Robotic Automated Storage and Retrieval System (AS/RS)", International journal of computational Engineering Research, vol.3 issue 3, March 2013.

[5] HEUNGSOON FELIX LEE," Performance analysis for automated storage and retrieval systems", IIE Transactions, 1997.

[6] M.R. Vasili, S.H. Tang, N. Ismail, and S. Sulaiman," CLASS-BASED STORAGE ASSIGNMENTS FOR MINILOAD AS/RS WITH OPEN-RACK STRUCTURE", International Journal of Engineering and Technology, Malaysia, , Vol. 5, No. 2, pp. 118-128 ,2008. 
[7] E. Vijayaragavan, Sanketh Bhat, Abhishek Patel and Divyang Rana," ] Design and analysis of a mobile robot for storage and retrieval system", 2nd International conference on Advances in Mechanical Engineering (ICAME 2018) IOP Publishing, IOP Conf. Series: Materials Science and Engineering 402,2018.

[8] Imén Kouloughli, Pierre Castagna, Zaki Sari,” Reducing retrieval time in Automated Storage and Retrieval System with a gravitational conveyor based on MultiAgent Systems", J. Appl. Comput, jacm.scu.ac.ir,vol. 4(1) ,pp.55-68, 2018.

[9] A. T. Rashid, F. R. Ali, and O. T. Rashid, "Design and Construction a Dynamic Store System using the Bezier Curve Algorithms", International Journal of Computer Applications, vol. 179, No. 42, pp. 22-29, 2018.

[10] A. T. Rashid, F. R. Ali, and O. T. Rashid, "Software implementation of a static store system using the digital differential analyzer algorithm", International Iraqi Conference on Engineering Technology and their Applications, The Islamic University - Najaf - Iraq, 2018.

[11] F. R. Ali, and A. T. Rashid, "Design and implementation of static and dynamic objects store systems using line follower robots", International Conference on Advances in Sustainable Engineering and Applications, Wasit university - Iraq, 2018.

[12] F. R. Ali, and A. T. Rashid, "Software implementation of objects store system using line follower robots", Second Al-Sadiq International Conference on Multidisciplinary in IT and Communication Science and Applications, 2017.

[13] F. R. Ali, and A. T. Rashid, "Design and Construction Objects Store System using line follower robots", International Journal of Computer Applications, vol. 181, No. 15, pp. 27-35, 2018.

[14] JAINIL PRAJAPATI, HARSHAL GOYAL, JEEL PATEL, APURVA GANDHI, SAMARTH BHADUWALA," AUTOMATED STORAGE AND RETRIEVAL SYSTEM FOR EDUCATIONAL PURPOSE- A REVIEW",

[15] M. R. Vasili, Sai Hong Tang and Mehdi Vasili ,"Chapter 8 -Automated Storage and Retrieval Systems: A Review on Travel Time Models and Control Policies",

[16] OUHOUD. A, GUEZZEN. A, SARI. Zaki.," Comparative Study between Continuous Models and discrete models for Single Cycle Time of a Multi-Aisles Automated Storage and Retrieval System with Class Based Storage", IFAC-PapersOnLine at www.sciencedirect.com , pp.1341-1346,2016.

[17] Latéfa GHOMRI \& Zaki SARI," Mathematical modeling of retrieval travel time for flow-rack automated storage and retrieval systems", IFAC (International Federation of Automatic Control) Hosting by Elsevier , j.ifacol,2015 .

[18] Tony Wautersa, Fulgencia Villab, Jan Christiaensa, Ramon Alvarez Valdesc, Greet Vanden Berghea," A decomposition approach to dual shuttle automated storage and retrieval systems",
[19] Roodbergen, K. J., Vis, I. F.,” A survey of literature on automated storage and retrieval systems", . European Journal of Operational Research, 2009.

[20] Miss. Anuradha S. Parab, Prof. P. N. Gore, "A Review on Automated Storage and Retrieval System", International Research Journal of Engineering and Technology (IRJET), Vol. 05, Issue 12, 2018.

[21] Tom Meyers," What to consider for a successful AS/RS investment white paper", Intelligent. All rights reserved. 2016.

[22] Liam O'shea," development of an automated storage and retrieval system in a dynamic knowledge environment ", MSC in Waterford institute of technology, 2007.

[23] Mohammed Ruzayqat,” DESIGNING A CELLULARBASED FULLY AUTOMATED CASE PICKING SYSTEM", PhD, April 2016.

[24] [BYUNG CHUN PARK," TECHNICAL NOTE Optimal dwell point policies for automated storage/retrieval systems with dedicated storage “,IIE Transactions ,1999.

[25] Jeroen P. van den Berg," Analytic expressions for the optimal dwell point in an automated storage/retrieval system", Int. J. Production Economics, Vol.76, pp.13-25, 2002.

[26] Ankit Agarwa and A.K. Madan," A Review of Analytical Travel Time Models in Automated Storage and Retrieval Systems", Journal of Basic and Applied Engineering Research, Volume 2, Number 16; AprilJune, pp. 1372-1376, 2015.

[27] L Min-Hong Han, Leon F. McGinnis, Jin Shen Shieh, John A. White," ON SEQUENCING RETRIEVALS IN AN AUTOMATED STORAGE/RETRIEVAL SYSTEM", School of Industrial and Systems Engineering, Georgia Institute of Technology , FEB, 2 1,1985 .

[28] S. Kulturel, N. Ozdemirel, C. Sepil, and Z. Bozkurt," Experimental investigation of shared storage assignment policies in automated storage/retrieval systems", ," IIE Trans. (Institute Ind. Eng., vol. 31, no. pp. 739-749, March 2015.

[29] Agarwal and A.K. Madan," A Review of Analytical Travel Time Models in Automated Storage and Retrieval Systems", Journal of Basic and Applied Engineering Research, Volume 2, Number 16; April-June, pp. 13721376, 2015.

[30] C. J. Malmborg," Storage assignment policy tradeoffs", International Journal Of Production Research,vol. 34, no. 2, pp. 363-378, 1996.

[31] W. H. Hausman, L. B. Schwarz, and S. C. Graves, "Optimal Storage Assignment in Automatic Warehousing Systems”, Manage. Sci., vol. 22, no. 6, pp. 629-638, 1976.

[32] Sepastian Henn, soren Koch and Gerhard wascher," order batching in order picking warehouse a survey of solution approaches", http://www.fww.ovgu.de/femm ,Bezug uber den Herausgeber,Germany , No. 01,2011 . 